\title{
O catolicismo entre a tradição e a reinvenção: novas comunidades, leigos consagrados e vida eremítica na Arquidiocese de Belo Horizonte
}

\author{
Catholicism between the tradition and the reinvention: new communities, \\ lay consecrated and eremitic life in the Archdiocese of Belo Horizonte
}

Carlos Frederico Barboza de Souza*

\begin{abstract}
Resumo
O presente artigo tem como objetivo pensar a diversidade das expressões de consagração que ocorrem no catolicismo romano contemporaneamente e na Arquidiocese de Belo Horizonte, e que se encontram no compartilhamento dos espaços eclesiais entre formas novas de consagração, como as Novas Comunidades, e as antigas formas de consagração atualizadas na contemporaneidade, como a consagração laical e a vida eremítica. Apontam para expressões diferentes da ação apostólica e de compreensão do catolicismo, assim como da organização institucional. Assim sendo, discutir-se-á, inicialmente, a diversidade que compõe o catolicismo hodierno; em seguida, tecer-se-á considerações sobre o estatuto das novas formas de consagração, sobretudo, as Novas Comunidades, diferenciando-as de outras formas de consagração. Por fim, apresentar-se-ão algumas destas expressões de maneira concreta, expondo, brevemente, sua história, carisma e ação apostólica. A conclusão aponta para a percepção de uma lógica construtiva das experiências religiosas na relação entre catolicismo e realidades culturais/religiosas/filosóficas/teológicas circundantes, presentes nas diferentes formas de consagração, assim como para a existência de certa porosidade entre diferentes grupos contemporâneos, que constroem sentidos por meio de ressignificações. Para esta pesquisa, trabalhou-se a partir da fenomenologia da religião, com técnicas de coleta de informações pautadas em referenciais bibliográficos e digitais, além de entrevistas não estruturadas.
\end{abstract}

Palavras-chave: Catolicismo romano; consagração; novas comunidades; leigos consagrados; eremitismo.

\begin{abstract}
This article aims to reflect on the diversity of the expressions of consecration that occur in contemporary Roman Catholicism and in the Archdiocese of Belo Horizonte, that lies in the sharing of ecclesial spaces between new forms of consecration, such as the New Communities, and ancient forms of consecration updated in the contemporaneity, such as lay consecration and hermetic life. In this sense, the article points out to different expressions of apostolic action, understanding of Catholicism and institutional organization. Thus, the diversity that makes up today's Catholicism will initially be discussed; The status of the new forms of consecration, especially the New Communities, differentiating them from other forms of consecration present in Catholicism, will then be considered. Finally, the article will present some of these expressions in a concrete way, briefly presenting their history, charisma and apostolic action. The conclusion points to the perception of a constructive logic of religious experiences, in relation between Catholicism and the cultural, religious, philosophical and theological realities surrounding, present in the different forms of consecration, as well as the existence of a certain porosity between different contemporary groups, which construct meanings through resignifications. In this research, we worked from the perspective of the phenomenology of religion, with information collection techniques based on bibliographic and digital references, as well as unstructured interviews.
\end{abstract}

Key-words: Roman Catholicism; consecration; new communities; consecrated laity; eremitism.

Artigo submetido em 17 de março de 2019 e aprovado em 28 de agosto de 2019.

* Doutor em Ciência da Religião pela UFJF. Professor do PPGCR PUC Minas. País de origem: Brasil. E-mail: fred@pucminas.br 


\section{Introdução}

O catolicismo no Brasil tem se manifestado de forma bastante plural. ${ }^{1}$ Como afirma Carlos Rodrigues Brandão (1988), há diferentes modos de ser católico e de participar desta tradição religiosa. Isto porque as formas de vinculação ao catolicismo são plurais, indicando que, na atualidade, há "vários estilos culturais de 'ser católico"”. (BRANDÃO, 2004, p. 268). E “mesmo no interior de um catolicismo mais canônico, praticado em linha direta de relação com o corpo sacerdotal, subsistem modalidades de tendências não raro de difícil integração no corpus de doutrina, gestos e ritos de uma mesma religião e de uma mesma igreja”. (BRANDÃO, 2004, p. 268).

Nesse sentido, este artigo quer apresentar algumas formas de consagração existentes no catolicismo romano, a saber: Novas Comunidades e antigas formas de consagração atualizadas na contemporaneidade, como os Leigos, Virgens e Viúvas Consagrados e os Eremitas. Assim sendo, em um primeiro momento, será abordada a questão da diversidade religiosa que nasce do encontro da Igreja Católica Romana com a contemporaneidade e suas culturas e dinamismo social; em seguida, o foco estará em uma reflexão sobre as formas de consagração existentes na diversidade de que é composto o catolicismo atualmente. Por fim, serão apresentadas algumas expressões diferenciadas de consagração existentes no catolicismo contemporâneo, procurando expor brevemente um pouco da história e carisma da comunidade e um pouco de sua atuação apostólico-evangelizadora na Arquidiocese de Belo Horizonte.

\footnotetext{
${ }^{1}$ A diversidade presente no catolicismo não é uma novidade recente. O que é novo é a intensidade com que se manifesta na contemporaneidade e "o grau de diversidade dentro de uma única Igreja sob uma única liderança. [...] enquanto uma igreja única, a diversidade católica se destaca das demais e impressiona os analistas." (MARIZ, 2006, p. 57). Portanto, "a novidade no catolicismo contemporâneo não seria, então, a sua diversidade, pois essa tem sido uma constante, mas a dimensão dessa diversidade." (MARIZ, 2006, p. 58).
} 


\title{
1 Comunidade eclesial e diversidade de expressões do catolicismo romano no Brasil
}

Segundo Faustino Teixeira (2009, p. 19), "a plasticidade dos modos de ser católico no Brasil é a expressão de uma genuinidade brasileira, ${ }^{2}$ caracterizada pela grande ampliação das possibilidades de comunicação com o sagrado ou com o 'outro mundo". Nesse sentido é que se pode afirmar a existência de "catolicismos", que Faustino Teixeira (2009, p. 20) tipifica em quatro modelos: o catolicismo santorial, o erudito ou oficial, o catolicismo dos reafiliados e o catolicismo midiático, revelando a "própria 'identidade católica' que se diversifica" (SANCHIS, 2001, p. 12):

\begin{abstract}
Diversificação ativa, que não se reduz à do espaço geográfico, e que multiplica, até no interior da mesma complexa instituição, a Igreja católica por exemplo, as instâncias de referência identitária, os sistemas de atribuição de sentido, as famílias de espírito reagrupadas em torno de visões do mundo e etos institucionalizados, as etiquetas religiosas coletivas, os produtos investidos de poder espiritual consensual, por um lado. [...] Por outro lado - talvez até sobretudo analisem-se também, no interior mesmo dessas agremiações e movimentos, as maneiras diversas de aderir a esses consensos, de pertencer a esses coletivos, de compartilhar dessas visões do mundo e de adotar a orientação desse etos; as modalidades da crença nesses sentidos e nesses poderes; os modos, exclusivos ou múltiplos, de afirmar, distinguir e/ou combinar essas identidades, seja assumindo uma posição estável, seja tateando num itinerário à procura, através de mil caminhos, de um horizonte... Níveis vários de diversidade, que se reduplicam, cruzando-se. (SANCHIS, 1997, p. 28-29).
\end{abstract}

A existência desta diversidade de expressões no seio do catolicismo brasileiro aponta para uma perspectiva que se apresenta na contemporaneidade acerca da apropriação da fé na vida dos praticantes de uma determinada religião. Pois,

muito mais do que em anos passados, até mesmo as religiões tidas como tradicionais e consagradas tendem a se diferenciar bastante no interior de suas ortodoxias, de modo a oferecerem, sobretudo aos leigos, uma multiplicidade de afiliações de significado e prática da fé [que] envolvem novos significados de crença e novas sensibilidades de fé a respeito do próprio sentido do sagrado. A respeito da lógica das relações entre a pessoa e os seres celestiais e, finalmente, a respeito da

\footnotetext{
${ }^{2}$ Embora haja elementos genuínos de brasilidade nos fenômenos presentes no catolicismo que aqui se vive, não se pode perder de vista que esta diversidade também se apresenta no catolicismo em nível mundial, haja vista a diversidade de expressões que podem ser percebidas em fenômenos como as Jornadas Mundiais da Juventude.
} 
gramática espiritual e prática das regras de adesão e das opções de destino pessoal, com sentidos e valores: ético, social ou político, e voltadas para 'o compromisso com o Mundo'. (BRANDÃO, 2004, p. 278).

Assim sendo, podemos afirmar, com Carlos Rodrigues Brandão, que há uma grande "polissemia religiosa" nestes últimos anos, fruto de uma flexibilização das possibilidades de adesão religiosa no seio das tradições religiosas, fenômeno que também ocorre no interior da tradição católicoromana” (BRANDÃO, 2004, p. 279).

Essa grande polissemia religiosa também pode ser pensada como consequência, segundo Danièle Hervieu-Léger (2008), de fortes processos de subjetivação e individualização que se estabeleceram na modernidade como consequência da desregulação do campo religioso na contemporaneidade. Esses processos favorecem que as identidades religiosas não sejam mais herdadas ou, pelo menos, que a dimensão do "herdado" encontre diminuída sua força -, mas construídas, devido a sucessivas transformações das "referências coletivas", no meio de "rupturas de memória" e "reorganização de valores", por meio dos quais os indivíduos constroem sua fé através de procedimentos de bricolagem e de desregulação das práticas e vivências religiosas.

Por sua vez, Pierre Sanchis irá sugerir que parte dessa polissemia também surge devido à construção de porosidades nas pertenças religiosas, o que permite "intensos cruzamentos de fluxos de caráter religioso [...] abertura das audiências à mensagem do “outro"' (SANCHIS, 2001, p. 31), apesar da forte necessidade de marcação identitária hoje presente em nossa sociedade, manifestada em diversas expressões fundamentalistas e integristas.

E, por fim, pode-se acrescentar, segundo Cecília Mariz, que a diversidade experimentada hoje no catolicismo pode passar por algumas questões internas à Igreja Católica, como a tensão entre hierarquia e leigos, que pode gerar a criação de grupos que procuram relativa autonomia em relação ao Vaticano e à hierarquia eclesiástica. 
Neste aspecto, Cecília Mariz (2006, p. 58-60), a quem sigo quase que literalmente nas formulações abaixo, propõe a identificação de quatro elementos que têm favorecido a diversidade no seio do catolicismo hodierno no Brasil: 1) a pluralidade de "campanhas” internas da Igreja Católica. Neste tópico ela elenca três campanhas principais: a romanização, a campanha promovida pela Teologia da Libertação e o movimento de Renovação Carismática Católica; 2) a "barganha cognitiva" com a cosmovisão moderna. Neste tópico, ela vai afirmar que a modernidade contemporânea, por si só, já é plural e acaba gerando visões plurais com impacto nas tradições religiosas; 3) o surgimento de indivíduos com "carismas" especiais e a ocorrência de eventos "sobrenaturais", o que interessa particularmente a este artigo, devido ao surgimento de Comunidades de Vida e Aliança e diversos outros grupos associados ao carisma específico de um fundador ou fundadora; 4) a ingerência de instituições não religiosas e não católicas no mundo católico, como prefeituras e agências de turismo ao redor de grandes festas populares católicas.

Nesse cenário vive-se certo paradoxo: se, por um lado, as instituições religiosas entram em crise, perdem parte de sua força, por outro, simultaneamente, abrem possibilidades para a construção de novas configurações religiosas. Ou seja, se, por um lado, a perda da memória (características das sociedades amnésicas) e da capacidade de transmissão de uma tradição religiosa acaba por gerar pouca adesão às religiões constituídas e estabelecidas na sociedade, por outro, as “trajetórias de identidades” se realizam por meio das escolhas dos sujeitos, através de uma articulação livre de quatro dimensões: comunitária, ética, cultural e emocional. Nesse sentido, geram novas e diversificadas adesões.

Esta perda de força das instituições religiosas na contemporaneidade, segundo Peter Berger, é decorrente da "perda de objetividade" do religioso hoje, o que geraria um enfraquecimento das certezas e das verdades religiosas. Entretanto, esse mesmo "enfraquecimento" parece vir acompanhado, também, de forte pluralismo de expressões religiosas, o que explicaria, em parte, a forte visibilidade religiosa na atualidade, assim como a diversidade de expressões e 
certo ressurgimento do Sagrado em tempos que se esperaria o aprofundamento do desencantamento ou da secularização religiosas (BERGER, 1985).

Assim, pode-se afirmar, com Carlos Rodrigues Brandão, que

o Catolicismo parece ser a religião com a mais aberta capacidade de ajustamento aos "novos tempos", embora seja a confissão religiosa que mais "perde fiéis para as outras". Quando observada de perto, vemos como ela se abre e se permite diversificar, de modo a oferecer, em seu interior, quase todos os estilos de crença e de prática da fé existentes também fora do Catolicismo. (BRANDÃO, 2004, p. 282).

E essa "abertura" e "plasticidade" observadas no catolicismo propicia, como afirma Cecília Mariz, compreender que "a queda na proporção de católicos parece estar sendo acompanhada por um relativo reavivamento religioso, e mais ainda por uma intensificação da diversidade na experiência de ser católico" (MARIZ, 2006, p. 53). 3 O contexto atual, portanto, gera impactos no catolicismo propiciando enorme diversidade de compreensões e de formas de se viver o que se entende como catolicismo, uma vez que

o tempo cultural em que vivemos e para onde nos dirigimos, inclui cada vez mais um número maior de estilos de espiritualidades, de outros sistemas de sentido, de combinações pessoais e coletivas de saberes e valores que não apenas permitem, mas obrigam a própria pessoa-religiosa a interações de sentido, a integrações de escolhas, a indeterminações de seu próprio destino como um indivíduo e uma identidade. [...] Este fenômeno de retorno ao sagrado, revestido agora de uma extraordinária plasticidade, de um antes impensável poder de criação e de diferenciação, envolve pessoas, grupos sociais e comunidades culturais as mais diversas. (BRANDÃO, 2004, p. 284).

E se o momento contemporâneo apresenta facetas de diversidade, essas se realizam, é bem verdade, devido a processos de subjetivação individualizantes, mas também possui outras facetas: a diversidade representa, igualmente, buscas criativas de inculturação da fé e de suas práticas e linguagens, assim como do desejo de diálogo com as culturas e realidades com as quais os praticantes da fé católica se deparam cotidianamente.

\footnotetext{
${ }^{3}$ Este "reavivamento" católico pode ser entendido ainda, segundo Cecília Mariz, a partir do paradigma do mercado religioso de Stark e lannaccone, como consequência da competitividade instalada no Brasil a partir da realidade do pluralismo religioso e das perdas de fieis que têm caracterizado o catolicismo nos últimos censos do IBGE. Diante da perda de hegemonia e monopólio, há um fenômeno de "renovação" e "aumento do fervor" (MARIZ, 2006, p. 55).
} 
Por outro lado, a diversidade presente na Igreja Católica não é, necessariamente, sinal de fragmentação, embora essa realidade também se faça presente. Sinaliza, outrossim, a partir de um olhar teológico, que "assim como Deus é um só na diversidade das três pessoas, também a Igreja é unidade na diversidade”. (CNBB, 2016, n. 151). Ou seja, a diversidade com que se constitui e manifesta o catolicismo hodiernamente, em parte, é tradução de sua vocação trinitária e manifestação desta sua dimensão. Como afirma Leonardo Boff,

Há um anseio humano fundamental: de participação, de igualdade, de respeito às diferenças e de comunhão com tudo e com Deus. A comunhão dos divinos Três propicia uma fonte de inspiração na realização destes ancestrais anseios de todas as pessoas e de todas as sociedades. Cada Pessoa divina participa totalmente das outras duas: na vida, no amor e na comunhão. Cada uma delas é igual em eternidade, em majestade e em dignidade; nenhuma é superior ou inferior à outra. Embora iguais na participação da vida e do amor, cada Pessoa é distinta da outra. O Pai é distinto do Filho e do Espírito Santo e assim sucessivamente com cada Pessoa. Mas esta distinção permite a comunhão e a mútua entrega. As Pessoas são distintas para poderem dar de sua riqueza às outras e assim formarem a comunhão eterna e a divina comunidade. A Santíssima Trindade é a melhor comunidade. (BOFF, 1988, p. 109-110).

Assim, a dimensão trinitária, que incita à comunhão e a estabelece como ideal eclesiológico, é modelo da vida cristã, com fortes implicações sociais e também eclesiais, no sentido de que a valorização da diversidade e da existência do diferente, ao mesmo tempo apela para a comunhão, sentido maior da vida em comunidade de fé na perspectiva cristã. Se a "Igreja possui tantos rostos quantas encarnações ela conheceu ao longo de sua história” (BOFF, 1988, p. 111), estes precisam ser acolhidos e compreendidos na lógica do enriquecimento mútuo que somente a diversidade propicia.

\section{Novas Comunidades: formas diferenciadas de consagração e vocações eclesiais de doação plena ${ }^{4}$}

\section{Segundo o documento Vita Consecrata (doravante VC), a consagração é}

\footnotetext{
${ }^{4}$ Esta expressão é utilizada por Roberto Almada ao tentar abarcar diversas formas de doação laical nas Igrejas, comunidades e instituições que se dedicam ao bem da humanidade (ALMADA, 2013, p. 91-92). Aqui, seu sentido é ampliado para todos os tipos de vocação que se orientam para uma dedicação integral ao serviço pastoral / apostólico / evangelizador e à comunidade eclesial, exigindo um abandono das atividades profissionais e laborais; ou a uma dedicação que implique em um compromisso esponsal com Deus e a comunidade eclesial, que se concretiza em uma vida casta e celibatária.
} 
um dom de Deus Pai à sua Igreja, por meio do Espírito. Através da profissão dos conselhos evangélicos, os traços característicos de Jesus - virgem, pobre e obediente - adquirem uma típica e permanente 'visibilidade' no meio do mundo, e o olhar dos fiéis é atraído para aquele mistério do Reino de Deus que já atua na história, mas aguarda a sua plena realização nos céus. (VC 1).

Nas trilhas desse documento, o que caracteriza uma consagração é a profissão, por meio de votos, dos conselhos evangélicos de pobreza, obediência e castidade, além de uma disposição para ser testemunha no "meio do mundo" (VC 25; 33). Some-se a estas características a dimensão da vida fraterna, "em virtude da qual as pessoas consagradas se esforçam por viver em Cristo com 'um só coração e uma só alma' (At 4,32), se apresenta como uma eloquente confissão trinitária” (VC 21). 5

As Novas Comunidades $^{6}$, por sua vez, trazem uma perspectiva diferenciada e são denominadas na Vita Consecrata como "novas expressões de vida consagrada" (n. 12) e "novas formas de vida evangélica" (n. 62), podendo ser consideradas, também, "vocações eclesiais de doação plena" (ALMADA, 2013, p. 91). Sua singularidade e originalidade se encontram, sobretudo, na prevalência laical em sua forma de organização eclesial (JOÃO PAULO II, 1998, p. 6), frutos da eclesiologia conciliar e da valorização do laicato ou de certas expressões do laicato. Trata-se, portanto, de uma forma associativa relativamente nova, que recebe esta denominação para diferenciar-se das comunidades paroquiais, das Comunidades Eclesiais de Base, das comunidades religiosas e dos Novos Movimentos Eclesiais. Em termos canônicos, não se encontram definidas, diferentemente dos "novos movimentos".

No seio das Novas Comunidades, podemos distinguir dois tipos de expressões: Comunidades de Vida e Comunidades de Aliança. As primeiras se articulam ao redor de leigos, casais e consagrados que vivem sob o mesmo teto, dividindo seu sustento e se comprometendo igualmente pela manutenção da Comunidade de Vida; já as segundas são compostas por pessoas que aderiram

\footnotetext{
${ }^{5}$ Conferir também: (VC 41-42).

6 "Segundo matéria publicada pelo jornal Settimana News, em abril de 2017, um Censo realizado em 2010 (o primeiro desde que esse tipo de associação surgiu), pelo teólogo italiano Giancarlo Rocca, os números das Novas Comunidades seriam os seguintes: haveria registros da Santa Sé de 775 Novas Fundações ou Novas Comunidades, das quais 205 estariam nos Estados Unidos, 200 na Itália, 161 na França, 44 no Brasil e 20 na Espanha. A matéria ainda informa que o Censo constatou uma considerável estabilização dessas comunidades nos últimos vinte anos (pontificado de João Paulo II)" (SILVA, 2018, p. 51).
} 
ao carisma de uma comunidade, mas continuam vivendo em suas casas e mantendo sua vida profissional, embora vinculadas à Comunidade.

A forma organizativa das Novas Comunidades se estabeleceu a partir de 30 de novembro de 1990, quando um decreto do Pontifício Conselho para os Leigos erigiu a Catholic Fraternity of Charismatic Covenant Communities and Fellowships como uma Associação Privada de Fiéis Cristãos de Direito Pontifício. Em nível nacional, a organização se dá por meio da FRATER, presidida por Monsenhor Jonas Abib (FRATERNIDADE DAS NOVAS COMUNIDADES, 2008).

Além disso, frequentemente,

no fato de se tratar de grupos compostos de homens e mulheres, de clérigos e leigos, de casados e solteiros, que seguem um estilo particular de vida, inspirado às vezes numa ou noutra forma tradicional ou adaptado às exigências da sociedade atual. Também o seu compromisso de vida evangélica se exprime em formas diversas, manifestando-se, como tendência geral, uma intensa aspiração à vida comunitária, à pobreza e à oração. No governo, participam clérigos e leigos, segundo as respectivas competências, e o fim apostólico vai ao encontro das solicitações da nova evangelização. (VC 62).

E mais: de acordo com Rejane Maria Dias de Castro Bins (2016, p. 9), as Novas Comunidades se caracterizam por alguns outros elementos, já presentes nos documentos conciliares (Lumen gentium, IV; Gaudium et spes, 43; Presbyterorum ordinis, 8; e o decreto sobre o apostolado dos leigos, Apostolicam actuositatem), tais como: o apostolado leigo - interno e externo -, o direito de livre associação, a comunhão interna e com os membros da hierarquia eclesiástica, a necessidade imperiosa de formação e a disposição para participar da missão eclesial de evangelizar.

Canonicamente, entretanto, podem situar-se como Associações de Fiéis e sua normativa passa pela normativa destes tipos de associações (CNBB, 2005, n. 25.56), sendo que o Código de Direito Canônico lhes reconhece em três tipos diferentes: “1) associações públicas, erigidas pela autoridade eclesiástica; 2) associações privadas, erigidas pelos fiéis e aprovadas pela autoridade eclesiástica; 3) condomínios, que são associações privadas que não foram elevadas à personalidade jurídica na Igreja (cân. 310)”. (CNBB, 2005, n. 19). 


\title{
Ainda segundo o Código de Direito Canônico,
}

\begin{abstract}
$\mathrm{Na}$ Igreja existem associações, distintas dos institutos de vida consagrada e das associações de vida apostólica, nas quais os fiéis, clérigos ou leigos, ou conjuntamente clérigos e leigos, se empenham, mediante esforço comum, por alimentar uma vida mais perfeita e promover o culto público, a doutrina cristã ou outras obras de apostolado, isto é, iniciativas de evangelização, exercício de obras de piedade ou caridade, e animação da ordem temporal com espírito cristão. (CIC, 1983, 298).
\end{abstract}

As Associações de Fiéis e as Novas Comunidades podem ser pensadas como novos sujeitos eclesiais, que reúnem pessoas compromissadas por meio de formas particulares de consagração e que se pautam em novos carismas ao redor de um fundador ou fundadora. Com isso, pretendem, sobretudo, responder aos desafios pastorais e da evangelização que a contemporaneidade apresenta.

No entanto, embora a criatividade trazida pelo formato organizacional original e em expressões novas carismáticas, as Novas Comunidades, muitas vezes, representam posturas neoconservadoras, caracterizadas

\begin{abstract}
quando os diversos elementos da doutrina da Igreja Católica principalmente a da doutrina moral - são simplesmente reproduzidos, não considerando em geral o embasamento teológico, antropológico, cultural, implicado nas verdades da fé. Falta, por exemplo, nos conteúdos propostos para a formação dos afiliados, aquela criatividade de comunicar a doutrina católica em atitude de diálogo com a cultura atual, sabendo valorizar os sinais dos tempos: 'seu vazio teológico-doutrinal acaba fazendo católicos não só não evangelizados, como incapazes de uma missão em diálogo com o mundo e em espírito de cooperação com outras denominações religiosas e instituições civis'. (BRINGHENTI, 2001, p. 20) (FERREIRA, 2011).
\end{abstract}

E para "comunicar a doutrina católica em atitude de diálogo", é importante se pensar tanto em processos formativos quanto em ações apostólicas que decorrentes de um rico processo formativo possam gerar ações profundas e significativas de evangelização. Assim, em termos de ação pastoral/evangelizadora, urge que as Novas Comunidades e Associações de Fiéis sejam capazes de uma reflexão teológico-crítica a respeito de seu agir na Igreja e na sociedade, assim como um empenho de comunhão, sobretudo, com a igreja local e suas prioridades pastorais, inserindo-se em sua vida pastoral orgânica. 
Segundo o documento da IV Conferência do Episcopado LatinoAmericano de Santo Domingo, em seu no 102:

\begin{abstract}
Ante os riscos de alguns movimentos e associações que podem chegar a fechar-se sobre si mesmos, é particularmente urgente terem em conta os "critérios de eclesialidade" indicados na exortação póssinodal Christifideles Laici n. 30. É necessário acompanhar os movimentos em um processo de inculturação mais definido e estimular a formação de movimentos com perfil mais latinoamericano. (CONSELHO EPISCOPAL LATINO-AMERICANO, 1993, $\mathrm{n}^{\mathrm{0}}$ 102).
\end{abstract}

Essa última afirmação é válida, sobretudo, porque muitas das Novas Comunidades estão inseridas em movimentos de caráter internacional, cujas orientações e preocupações, muitas vezes, não se atentam para as questões das Igrejas locais.

Também o documento 105 da CNBB cita o Papa Francisco a este respeito: "não percam o contato com esta realidade muito rica da paróquia local e que se integrem de bom grado na pastoral orgânica da Igreja particular. Essa integração evitará que fiquem só com uma parte do Evangelho e da Igreja, ou que se transformem em nômades sem raízes”. (CNBB, 2016, n. 50). Para isto, a formação em comunhão com a Igreja local é fundamental: "convém que participem da formação desenvolvida na Igreja diocesana”. (CNBB, 2016, n. 221).

As observações acima chamam a atenção para que as Novas Comunidades evitem o considerar-se

autossuficiente, comportando-se de modo tal como se não fosse cristão autêntico quem não aderisse a tal associação ou movimento; risco de uma espiritualidade intimista, pois responde mais a aspirações pessoais do que a problemas concretos da vida social; risco de alienação e falta de envolvimento com os cristãos de alguma diocese, região ou país, pois a orientação de tais agregações, em geral, provém de um centro cultural diverso, com problemáticas também diversas; não devem esquecer a opção evangélica ou profética pelos pobres. (FERREIRA, 2011). 
Ou, como disse o então Cardeal Ratzinger, há ainda o risco de sua experiência ser "vivida não como uma das formas da vida cristã, mas como se fossem possuidores [...] da mensagem evangélica de modo integral: isso pode induzir a absolutizar o próprio movimento, identificando-o com a própria Igreja e interpretando-o como via para todos”. (RATZINGER, 1999, p. 49).

Nesse sentido, Faustino Teixeira, ao discutir o "catolicismo de reafiliados”, afirma sobre os movimentos eclesiais algo que também pode servir de reflexão para as Novas Comunidades: desempenham um “papel ambivalente' no interior da Igreja Católica. De um lado, insere-se numa estratégia de clara afirmação identitária e de zelo pela doutrina católica tradicional; de outro, favorece uma dinâmica espiritual que acaba incidindo numa perspectiva de autonomização e transversalidade com respeito ao catolicismo oficial" (TEIXEIRA, 2009, p. 24). Isto porque um elemento que pode ser pensado como característica de boa parte das Novas Comunidades é sua relação com os Novos Movimentos Eclesiais, compreendidos como "um tipo específico de organização que se insere na estrutura mais ampla da Igreja, mas sendo unificado, administrado internacionalmente e independente do clero local”, que além disso, "em geral, atua ou se dirige apenas a camadas ou setores específicos da Igreja ou da sociedade. Na maioria das vezes tem práticas e estilos uniformes e muitas vezes possui um fundador reconhecido". (MARIZ, 2003, p. 172).

$\mathrm{Na}$ perspectiva organizacional, no entanto, as Novas Comunidades caracterizam-se por apresentar uma forma inovadora na sua estruturação, pelo menos em alguns aspectos. De maneira geral, suas estruturas obedecem a um estatuto, no qual se encontram os procedimentos para a recepção e formação dos novos membros, assim como as atribuições e encargos de cada membro, as estruturas organizativas da comunidade, da convivência e das práticas de oração, assim como das modalidades de colaboração com a comunidade eclesial. Também é comum que nestes estatutos sejam explicitados o carisma e a forma de atuação evangelizadora da comunidade. A inovação é proveniente do forte 
cunho de agregação laical7, assim como da convivência, muitas vezes, entre celibatários, casais e clérigos, compartilhando uma mesma estrutura organizacional e uma mesma espiritualidade.

Em termos das Associações de Fiéis e Novas Comunidades, como em todo o catolicismo presente no território nacional, há também diversas "formas de particular variedade e vivacidade [...] bastante diferentes umas das outras”, mas com "profunda convergência na finalidade que as anima: a de participar responsavelmente da missão da Igreja" (ChL 29). Nesse sentido, a descrição que segue quer apresentar algumas das diversas expressões destas comunidades presentes na Arquidiocese de Belo Horizonte, que foram selecionadas devido à sua significância nacional e pelo fato de terem se originado na própria arquidiocese.

Nesta mesma arquidiocese, em sua perspectiva pastoral e administrativa, as Novas Comunidades situam-se no Vicariato Episcopal para a Ação Pastoral, em um conselho específico: o Conselho Arquidiocesano das Associações, Movimentos Eclesiais e Novas Comunidades (CAMENC).

\subsection{Comunidade Canção Nova}

Fundada por Monsenhor Jonas Abib em 2 de fevereiro de 1978, a Comunidade Canção Nova é "reconhecida pelo Pontifício Conselho para os Leigos como associação internacional privada de fiéis, dotada de personalidade jurídica (cfr. CIC, cân. 298-311; 321-329) e tem sua sede na cidade de Cachoeira Paulista/SP, Diocese de Lorena, São Paulo - Brasil”. (COMUNIDADE CANÇÃO NOVA, 2017, 1, § 1).

\footnotetext{
${ }^{7}$ A forma agregativa laical não é uma novidade da contemporaneidade. Basta pensarmos nos movimentos monásticos, com forte cunho laical, que estão no surgimento das ordens monásticas contemporâneas, assim como no movimento dos mendicantes, como o franciscano e carmelita, que em seus primórdios era composto majoritariamente por leigos. Também se pode pensar em uma diversidade de formas agregativas do laicato. O Cardeal Lucas Moreira Neves, quando prefeito da Sagrada Congregação para os Bispos, formulou uma tipologia para compreender as diversas expressões de agregação laical: grupos, associações e movimentos. Segundo Wagner Ferreira (2011), "os grupos têm como característica principal certa espontaneidade e liberdade na sua formação e desenvolvimento, na adesão e permanência dos membros, no ritmo e conteúdo das reuniões, nos objetivos concretos e imediatos, na disciplina. As associações, ao contrário, são, pela sua natureza, muito mais estruturadas naquilo que se refere às bases institucionais, os objetivos, a adesão dos membros, os projetos de ação. Os movimentos [...] estariam no meio: não Ihes faltam estruturas institucionais, porém o mais importante e definitório é, para estes, o fato de constituir-se em torno a uma ideia-força que continuamente impulsiona à ação; esta ideia-força é a mística que está em todos os membros e os congrega em torno de uma figura carismática que por primeiro encarnou-a e continuamente a propõe novamente".
} 
Centrada no viver em comunidade, pois a "vida comunitária faz parte da essência da vocação da Comunidade Canção Nova”, possui como vocação maior e preferencial a ação evangelizadora através dos meios de comunicação social. Entretanto, atua também "nas áreas da educação, da saúde, das artes, da cultura e da promoção social, com o objetivo específico de contribuir concretamente na transformação do ser humano e das estruturas sociais”. (COMUNIDADE CANÇÃO NOVA, 2017, p. 3).

Trata-se de uma comunidade formada por

mulheres e homens; jovens e adultos; solteiros, casados e celibatários, sacerdotes e diáconos, que assumem a vivência mais radical da consagração a Deus feita no Batismo e na Crisma, em função do apostolado, numa vida em comunidade, conforme o estado de cada um. Tal vivência inspira-se na prática dos conselhos evangélicos, adaptada à vida secular. (COMUNIDADE CANÇÃO NOVA, 2017, p. 2).

A integração "destes diferentes estados na Comunidade Canção Nova é uma dimensão essencial do carisma” (COMUNIDADE CANÇÃO NOVA, 2017, p. 35). Seus membros comprometem-se, por meio de uma promessa denominada "compromisso", realizada diante do presidente ou de seu delegado e que possui duas formas de ser realizada: a) "Núcleo", destinado aos que se dedicam ao apostolado de forma integral; b) "Segundo Elo", destinado aos que fazem uma aliança com o Núcleo e vivem seu compromisso com a Canção Nova nas condições ordinárias da vida, na família, profissão e vida social. (COMUNIDADE CANÇÃO NOVA, 2017, p. 8-9).

O caminho espiritual da Canção Nova, com forte influência da Renovação Carismática Católica, se caracteriza pelos seguintes elementos: o trabalho santificado, a oração ao ritmo da vida, o uso dos meios (manter a atenção e a busca de recursos necessários para "cultivar um relacionamento pessoal e profundo com Deus”) e os tempos fortes (COMUNIDADE CANÇÃO NOVA, 2017, p. 6). 
Encontram-se presentes em diversos países e estados brasileiros, sobretudo, nas regiões Sul e Sudeste. ${ }^{8}$ Sua chegada à Arquidiocese de Belo Horizonte ocorreu em 2001, onde realizam atividades na perspectiva dos meios de comunicação social, possuindo um canal de TV local aberto (TV Canção Nova, 45.1), no qual produzem e veiculam programações locais e em rede nacional. Além disso, colaboram com o Santuário da Piedade, retransmitindo missas lá realizadas.

\subsection{Comunidade Católica Shalom}

A Comunidade Católica Shalom é uma Associação Privada Internacional de Fiéis, fundada por Moysés de Azevedo Louro Filho na década de 80 do século passado juntamente com outros quatro jovens, tendo como co-fundadora Emmir Nogueira. Em 1980, durante a visita do Papa João Paulo II à Fortaleza, Moysés se sente inspirado a se dedicar à juventude. Dois anos depois, em 1982, funda a "Lanchonete do Senhor", em Fortaleza, no dia 9 de julho, "um lugar atraente onde os jovens tinham a oportunidade de experimentar momentos de oração, fraternidade e missão, crescendo assim em seu caminho de fé”. Com esta ação, seu objetivo era "criar uma interface que falasse a linguagem dos jovens, para criar uma ponte entre eles e uma experiência pessoal com Jesus Cristo e a Sua Igreja” (COMSHALOM.COM, 2019).

Sua ação evangelizadora é diversificada e plural, trabalhando com jovens, crianças, famílias, assim como no mundo da arte, da cultura, das ciências, da promoção humana e dos meios de comunicação, dentre outros. Em suma, como se encontra em seu site, atua "através de obras de misericórdia que toquem os diversos sofrimentos que as pessoas atravessam" (COMSHALOM.COM, 2019).

Composta por homens e mulheres, celibatários, solteiros, casados ou sacerdotes, diáconos e seminaristas, procuram dedicar sua vida à vivência comunitária e missionária. Do ponto de vista de organização, estrutura-se em duas dimensões complementares: a Comunidade de Vida e a Comunidade de Aliança, sendo que a primeira é "o núcleo central da Comunidade Shalom”

\footnotetext{
${ }^{8}$ Segundo dados de 2013, a Canção Nova mantinha 25 casas de missão no Brasil e no exterior, possuindo 644 membros na Comunidade de Vida e 322 na Comunidade de Aliança (SANTOS, 2014, p. 99).
} 
(COMUNIDADE CATÓLICA SHALOM, 2012, p. 71). Além destes dois formatos de adesão à Comunidade Shalom, também são possíveis duas outras formas de participação no "carisma Shalom": há os membros da Obra, que não professam votos, mas participam dos grupos de oração e eventos da comunidade; e os Amigos do Shalom, que moram em lugares nos quais a comunidade não está presente, porém, aderem ao seu “estilo" e formação.

Sua espiritualidade nasce de uma "experiência com Cristo" que,

Ao encontrar os discípulos no Cenáculo, Jesus Ressuscitado lhes diz: Paz a vós (Jo. 20,19), ou seja, Shalom! Em Jesus, esta saudação é uma real comunicação da Paz, isto é, de toda sorte de bênçãos espirituais e materiais, a felicidade perfeita que o Messias nos traz. É, enfim, o anúncio e a doação da salvação plena. (COMUNIDADE CATÓLICA SHALOM, 2012, Preâmbulo).

Inspirando-se em Francisco de Assis e Teresa de Jesus, entendem que sua vocação se sustenta em um tripé: contemplação, unidade e evangelização. Por meio da contemplação busca-se a "vida de intimidade com Deus", que é o âmago da vida comunitária e é sustentada por meio de uma vida de oração e do cultivo de um "amor esponsal” com Deus.

A Comunidade Católica Shalom, com forte atuação no Nordeste brasileiro, está presente em mais de 40 países e quase todos os estados brasileiros, 9 tendo importante papel junto à Santa Sé ao ocupar 4 cargos de destaque (SILVA, 2019, p. 44).

Tem sua personalidade jurídica reconhecida pelo Vaticano em 22 de fevereiro de 2007 e seus estatutos aprovados definitivamente em fevereiro de 2012.

\footnotetext{
${ }^{9}$ Segundo dados do site da Comunidade Shalom, em 2012 ela possuía 980 membros na Comunidade de Vida, 4323 na Comunidade de Aliança, presentes em 42 dioceses em 19 estados brasileiros e em 23 cidades de 19 países, contendo, ao todo, 5303 membros.
} 


\subsection{Filhos e Filhas da Pobreza do Santíssimo Sacramento (Toca de Assis)}

Os Filhos e Filhas da Pobreza do Santíssimo Sacramento, conhecidos como Toca de Assis ${ }^{10}$, foram fundados pelo então seminarista estigmatino - e atualmente presbítero - Roberto José Lettieri, em 13 de maio de 1994, na cidade de Campinas, SP. Trata-se de uma Associação Pública de Fiéis, cujo carisma se centra na adoração contínua à Eucaristia, na vida de pobreza radical e no serviço e solidariedade aos pobres, principalmente, às pessoas em situação de rua, denominados por eles de "sofredores ou irmãos de rua". Em suas casas acolhem as pessoas pobres, que com eles convivem, e, em seus trabalhos com os sofredores de rua, partilham alimentos, roupas, cortam cabelos e unhas, cuidam das feridas, conversam, etc.

Seus Patronos inspiradores são: São Francisco de Assis, Santa Catarina de Gênova, São Pio de Pietrelcina e a Beata Alexandrina de Balasar.

Encontram-se presentes em quase todo o Brasil, divididos em regiões administrativas ou Centrais Regionais, que congregam suas diversas casas. Além disso, também se fazem presentes em outros países, onde desenvolvem os mesmos tipos de atividades.

Em relação às suas casas, é interessante perceber que há uma "especialização" quanto à atividade que desenvolvem. Assim, as casas São Pio (masculinas) e Virgem Mãe dos Pobres (femininas) se dedicam à população de rua que possua dificuldade de locomoção ou que possua algum tipo de doença grave ou terminal; as casas São José (masculinas), acolhem a população de rua com uma condição de saúde melhor; as casas Nossa Senhora das Dores (femininas) acolhem homens e mulheres em fase de doença terminal ou com impossibilidades de auto cuidado; as casas Bom Samaritano (masculinas) servem como casas de semiacolhimento; as casas fraternas Sacramento do Amor são casas femininas de semiclausura; há também sítios fraternos, em regiões mais afastadas dos centros urbanos, que se dedicam à pessoas que

\footnotetext{
${ }^{10}$ O nome "Toca de Assis" nasce a partir do início do franciscanismo. Em seu site consta que se inspirou na narrativa da Legenda dos Três Companheiros, na qual se diz que Francisco com seus primeiros seguidores viviam em "uma toca ou cabana abandonada". Outra origem do nome Toca se associa à percepção do Pe. Roberto de que as pessoas de rua se abrigavam em "tocas" de papelão ou se "entocavam" em casas em ruínas (TOCA DE ASSIS, 2019; PORTELA, 2009, p. 40-41).
} 
precisam de certo distanciamento da sociedade para se cuidarem, como os dependentes químicos. Nestas casas, normalmente, se localizam seus noviciados. Também possuem em Barreto/SP, uma casa específica para cuidar de presbíteros idosos ou doentes. (PORTELA, 2009, p. 43).

Junto à Associação de fiéis, há uma comunidade de aliança, denominada de Fraternidade Toca de Assis, que é responsável por diversos apoios à Associação, sobretudo, os de ordem financeira.

$\mathrm{Na}$ arquidiocese de Belo Horizonte, o ramo masculino chega em 1999. Já o ramo feminino se faz presente nesta circunscrição a partir de 8 de agosto de 2001. Ambas as comunidades realizam as atividades que são comuns à Toca de Assis, já mencionadas acima.

\subsection{Arautos do Evangelho}

Os Arautos do Evangelho surgem na cidade de São Paulo, Diocese de Campo Limpo, em 21 de setembro de 1999, pelas mãos de seu fundador, Monsenhor João Scognamiglio Clá Dias. ${ }^{11}$ Trata-se de uma Associação Privada Internacional de Fiéis de Direito Pontifício, com ereção canônica de 22 de fevereiro de 2001, durante a solenidade da Cátedra de São Pedro. Segundo informação constante em seu site, foi a primeira associação internacional a ser reconhecida canonicamente no novo milênio.

Presentes em 78 países (ZANOTO, 2011, p. 280), no Brasil se encontram em diversos estados, sendo compostos por homens e mulheres, que vivem em comunidades separadas e adotam um estilo de vida consagrada. Embora não professem votos e permaneçam no estado laical - com exceção de alguns que se tornam presbíteros -, assumem o celibato e a castidade, dedicando-se integralmente ao trabalho evangelizador. Dentre seus membros, também se encontram os Cooperadores, que "não podem comprometer-se plenamente com os objetivos [da comunidade], devido a seus compromissos sacerdotais, ao fato

\footnotetext{
${ }^{11}$ Em agosto de 1997, sob a liderança de João Scognamiglio Clá Dias e com certa ligação com a Sociedade Brasileira de Defesa da Tradição, Família e Propriedade (TFP), é fundada a Associação Cultural Nossa Senhora de Fátima. Dessa Associação é que surgem os Arautos do Evangelho, dois anos mais tarde.
} 
de pertencerem a algum instituto de vida consagrada ou sociedade de vida apostólica, ou a seus deveres matrimoniais ou profissionais”. (ARAUTOS DO EVANGELHO, 2019).

Sua missão se relaciona à busca da santidade, da perfeição e da colaboração com a evangelização, centrando-se em uma espiritualidade fincada em três pilares: a Eucaristia, Maria e o Papado. E seu carisma, a partir de uma visão arquitetônica, harmônica e hierárquica da ordem da Criação, visível e invisível, busca viver o amor à verdade (verum), à bondade (bonum) e à beleza (pulchrum) do Universo, enquanto reflexos de Deus. Além disso, a busca da beleza, a "pulcritude", que deve marcar a vida cotidiana, os relacionamentos no interior da comunidade, as celebrações litúrgicas e manifestar-se na ação evangelizadora por meio da arte e da cultura, sobretudo, através do teatro e da música.

Estabelecem-se na Arquidiocese de Belo Horizonte a partir de 11 de junho de 2002, desenvolvendo atividades em paróquias em que são convidados pelos respectivos párocos. Neste sentido, atuam na formação de grupos do oratório do Imaculado Coração de Maria; também realizam cursos preparatórios para a consagração a Jesus por Maria, segundo o método de São Luís Maria Grignion de Montfort; possuem o Coral dos Anjos, dos cooperadores dos Arautos de Belo Horizonte, que vêm se apresentando em várias paróquias, quer na animação litúrgica das Missas, quer em cantatas de Natal e em festas de padroeiros; cultivam a devoção dos 5 Primeiros Sábados, em honra do Imaculado Coração de Maria, promovida mensalmente na Casa dos Arautos do Evangelho; efetuam visitas à paróquias da imagem peregrina do Imaculado Coração de Maria; e, por fim, fazem visitas a hospitais por ocasião do Natal.

\subsection{Comunidade Católica Árvore da Vida}

A Comunidade Católica Árvore da Vida foi fundada por Rodrigo Serva Maciel em Belo Horizonte, no dia 21 de junho de 1998, e procura, em seu cotidiano, inspirar-se na vida monástica. A árvore da vida é a cruz de Jesus Cristo, que é vida e deve ser levada a todos os necessitados e aos lugares em que se impera a morte, pois Cristo sofre em todos os sofredores: "no faminto, no 
desempregado, no deprimido, no doente, no descrente, no materialista, no ateu, no menor abandonado, no sem-teto, no católico mal formado, na família atacada por mentalidades perversas, no jovem que sofre pela falta de referências e pelo vazio interior”. (COMUNIDADE ÁRVORE DA VIDA, 2019).

É composta por homens e mulheres, celibatários, casados e solteiros, vivendo em comum ou podendo cada um viver em sua casa, porém, todos compartilhando o mesmo carisma, espiritualidade, missão e fins apostólicos.

Em termos de espiritualidade, seus membros buscam a intimidade com Deus, cultivando a "amizade com Jesus" e um "amor esponsal". Inspiram-se em Teresinha do Menino Jesus e da Santa Face e em São Bento, cuja regra por ele elaborada é compreendida como uma referência para comunidade. Também inspirados em sua experiência, suas casas são denominadas de mosteiros. E desde 2018 há uma casa de missão, em Moçambique.

Em 2011 tem a aprovação de seu estatuto por Dom Walmor Oliveira de Azevedo e, logo após a criação do Vicariato Episcopal para a Ação Missionária (VEAM), compõe o seu conselho com a seguinte atividade missionária: a partir da realidade da Arquidiocese de Belo Horizonte e da atividade de evangelização necessária junto às vilas e favelas da Região Metropolitana de Belo Horizonte, realiza uma atividade de levantamento de dados das realidades de cada uma das quase 300 vilas e favelas relacionadas tanto pelo Censo demográfico do IBGE de 2010 quanto pelas paróquias que participaram do trabalho de informações ao VEAM.

\subsection{Comunidade Católica Nova Aliança}

A Comunidade Católica Nova Aliança é uma Associação Pública de Fiéis, de Direito Diocesano, aprovada no dia 22/02/2008 e fundada por Maria Ângela de Melo Nicolleti em Belo Horizonte. Teve seu início no ano de 1984, como um grupo de oração baseado na espiritualidade da Renovação Carismática Católica. Neste mesmo ano, no dia de Corpus Christi, é batizada com o nome de Nova Aliança. Após a organização de diversos cursos com o intuito evangelizador e de formação, estrutura-se como uma comunidade laical, na qual alguns membros 
vocacionados assumem compromissos mais específicos e estreitamente ligados ao patrimônio espiritual da Nova Aliança. São os denominados Fraternos.

Fazendo-se presente em missões nos estados de Minas Gerais, Distrito Federal, Tocantins, Pará e Ceará, sua missão é anunciar o Evangelho e despertar nas pessoas o amor à Igreja. Para isto, se dispõe a servir à Igreja e formar seus membros. Possui como santos de devoção, além de Nossa Senhora, Mãe da Nova Aliança, a São José, Santa Teresinha, São Bento, Santa Teresa de Ávila e o patriarca Abraão.

\section{Antigas formas de consagração atualizadas na contemporaneidade ${ }^{12}$}

Se as Novas Comunidades representam tentativas de diálogo com a contemporaneidade, tentativa esta que se expressa na busca de novos formatos de consagração, organização, vida em comum e ação apostólico-evangelizadora, no entanto, elas não são as únicas expressões desta busca inovadora no campo católico romano. Além de diferirem de outras expressões de consagração presentes no catolicismo, experimentam, à sua maneira, fenômenos semelhantes encontrados em outras representações da consagração.

Aqui, abordaremos algumas das expressões que são anteriores, inclusive, ao surgimento da vida monástica e da vida religiosa instituída, existente nos primórdios do cristianismo: os célebes ou continentes (que hoje podem ser reconhecidos, de alguma maneira, pelos leigos consagrados), as viúvas e as virgens consagradas, assim como a vida eremítica. Daí a opção por nomeá-las de “antigas formas de consagração", enquanto CODINA e ZEVALLOS (1987, p. 1838) irão agrupar as formas de consagração dos três primeiros séculos do cristianismo sob o título de "testemunho", incluindo o elemento martirial. E como continuam a existir ainda hoje, embora com reconfigurações em suas normativas, estilos possíveis de expressão e teologias, se optou por concebê-las como "atualizadas na contemporaneidade". Parte de sua atualização se deve às reconfigurações que o próprio contexto contemporâneo propicia. Porém, parte de sua atualização é devedora das transformações internas do próprio catolicismo, motivadas, em grande medida, pelo Concílio Vaticano II, que

\footnotetext{
${ }^{12}$ Agradeço ao frei Luiz Antônio Pinheiro, OSA, pela sugestão deste título.
} 
também lhes possibilitou novos marcos regulatórios e novas formas de expressão, e pela abertura "aos sinais dos tempos", expressão presente na Gaudium et spes, 11, quando afirma que "o Povo de Deus esforça-se por discernir nos acontecimentos, nas exigências e nas aspirações de nossos tempos, em que participa com os outros homens, quais sejam os sinais verdadeiros da presença ou dos desígnios de Deus" (VATICANO II, 1983, p. 153); também é uma expressão cara ao documento da Conferência Episcopal de Medellin, ocorrida em 1968 (CONSELHO EPISCOPAL LATINO-AMERICANO, 2010, p. 29), no qual se afirma que se deve ler na realidade o plano divino da salvação, uma vez que esta se constitui em "lugar teológico" no qual estão as “interpelações de Deus" (CONSELHO EPISCOPAL LATINO-AMERICANO, 2010, p. 7, 13).

Já no Novo Testamento se tem notícia de mulheres que se dedicam integralmente à comunidade, à oração, ao serviço e à vida com Deus (cf. At 21,89; I Tim 5,5.9-10; 1 Cor 7,8), vivendo, muitas vezes, um "ascetismo doméstico" 13, sem se retirarem do convívio social, pois "a cidade secular era o espaço em que se consolidava seu compromisso" (FIORES; GOFFI, 1993, p. 1171). ${ }^{14}$ Além disso, traduziam uma imagem da Igreja como esposa de Cristo (II Cor 11,2; Ap 19, 7-9; 21, 2-3.9; cf. também ESI, 1), "uma imagem escatológica especial da Esposa celeste e da vida futura, quando, finalmente, a Igreja viverá em plenitude o seu amor por Cristo Esposo" (VC 7). E mesmo no início do período patrístico há menções a elas, ${ }^{15}$ sendo que a partir do séc. IV já há um rito litúrgico de consagração realizado diante do Bispo diocesano.

Com o desenvolvimento do monacato cenobítico, a Igreja associa a vida virginal à vida comunitária. Com isto, "Paulatinamente, no curso dos séculos desapareceu a forma de vida originária da Ordo virginum, com seu típico enraizamento na comunidade local sob a orientação do Bispo diocesano”. (ESI, 5, tradução nossa). E somente com o Concílio Vaticano II é que o interesse por

\footnotetext{
${ }^{13}$ O Dicionário de Espiritualidade, ao estabelecer uma tipologia acerca da vida religiosa, tipificará com esta nomeação o caso das virgens e viúvas consagradas; ver Fiores; Goffi (1993, p. 1171).

${ }^{14}$ Conferir também Codina; Zevallos (1987, p. 18-19), em que se afirma: “O que mais caracteriza estes primeiros séculos é o estilo secular da vida dos cristãos".

${ }^{15}$ Há testemunhos muito antigos a este respeito, em cartas de Clemente Romano e Inácio de Antioquia.
} 
esta forma de consagração ressurge. ${ }^{16}$ E ressurge com vigor, experimentando, assim como as Novas Comunidades, uma riqueza de expressões e possibilidades inovadoras.

Entretanto, em relação à capacidade inovadora das Novas Comunidades há que se matizar em que sentido esta acontece. Isto porque estas novas formas de organização nem sempre podem ser consideradas inovadoras. Como questiona a pesquisadora Júlia Miranda, percebendo certo paradoxo no movimento da Renovação Carismática Católica que no meu entender pode ser aplicado às Novas Comunidades: "trata-se aqui de uma renovação que permanece presa à organização existente e à sua estrutura?" (MIRANDA, 1999, p. 53). Júlia Miranda faz este questionamento ao perceber que muitos grupos, numa perspectiva sociológica, mantêm-se atrelados a uma estruturação eclesial que, em boa parte, reproduz aspectos estruturais-institucionais do catolicismo, vivenciando pouco uma dimensão criativa que nasce da inovação e singularidade que um carisma propicia. E pode-se dar um passo além: muitas vezes, vivenciando de maneira limitada uma criatividade teológico-pastoral.

Em relação à vida eremítica, o mesmo se pode dizer quando se abordou as consagrações de célebes, virgens e viúvas em sua perspectiva criativa. $O$ impulso que alguns homens e mulheres têm e tiveram para viver na solidão não é novo na história da humanidade. Já se tem notícia de vida eremítica no século VI a.C., no Confucionismo e Taoísmo. Na Grécia antiga também se desenvolveu uma "filosofia acerca da solidão", assim como na tradição Hinduísta se apresenta como uma prática antiga.

\footnotetext{
${ }^{16}$ Na constituição conciliar sobre a liturgia, Sacrosantum concilium, n. 80, se dispõe que o rito litúrgico da consecratio virginum seja revisado. Em consequência, foi promulgado no dia 31 de maio de 1970, por mandato especial de Paulo VI, o novo Ordo consecrationis virginum, que entra em vigor no dia 6 de janeiro de 1971. O Código de Direito Canônico (can. 604) dispõe canonicamente sobre esta forma de consagração. Mais recentemente, o Catecismo da Igreja Católica (no 922-924) e o documento sobre a vida religiosa, Vita consecrata (números 7 e 42), contribuem clarificando "o lugar eclesiástico da Ordo virginum entre as outras formas de vida consagrada, pondo em relevo o vínculo peculiar que se estabelece entre as virgens consagradas e a Igreja particular y universal" (ESI, 7). Por último, em 2018, a Congregação para os Institutos de Vida Consagrada e as Sociedades de Vida Apostólica promulga a instrução Ecclesiae sponsae imago, que visa orientar e promover este tipo de consagração. Na atualidade, este modo de consagração floresce: "Um motivo de alegria e esperança é ver que hoje volta a florescer a antiga Ordem das virgens, cuja presença nas comunidades cristãs é testemunhada desde os tempos apostólicos." (VC 7). Segundo dados pontifícios mencionados pelo cardeal brasileiro João Braz de Aviz, "em 2016, durante o Ano da Vida Consagrada, uma estatística aproximada estimava a presença de mais de cinco mil virgens consagradas no mundo, em contínuo aumento." (SCARAMUZZI, 2018).
} 
Em termos do Cristianismo, o eremitismo remonta aos Padres e Madres do Deserto. É um dos primeiros tipos de vida consagrada masculina, juntamente com os célebes, ainda no século III a.C., iniciado por Santo Antão (250-365), o "Pai dos monges", que se inspirando no texto evangélico de Mt 19,21, abraça o ascetismo doméstico e, em seguida, retira-se para o deserto, assumindo uma vida eremítica. Entretanto, mais tarde, o Concílio de Trento proíbe este estilo de vida, sobretudo, os eremitas diocesanos, obrigando-os a entrarem para alguma ordem religiosa. A condição canônica acerca do eremitismo veio apenas com o Código de Direito Canônico de 1983, em seu cânon 603:

\begin{abstract}
$\S 1$. Além dos institutos de vida consagrada, a Igreja reconhece a vida eremítica ou anacorética, com a qual os fiéis, por uma separação mais rígida do mundo, pelo silêncio da solidão, pela assídua oração e penitência, consagram a vida ao louvor de Deus e à salvação do mundo.

$\S$ 2. O eremita, como dedicado a Deus na vida consagrada, é reconhecido pelo direito, se professar publicamente os três conselhos evangélicos, confirmados por voto ou por outro vínculo sagrado, nas mãos do Bispo diocesano, e se mantiver o próprio modo de vida sob a orientação dele. (CIC, 1983, 603).
\end{abstract}

A palavra eremita é proveniente do grego eremia e do latim eremus, que significa deserto. Portanto, eremita significa aquele que se retira ao deserto para uma vida de solidão, silêncio, oração e penitência. Também são chamados de anacoretas, ou seja, aqueles que são "sem coro", uma vez que o coro é uma característica do monacato cenobítico.

Há, entretanto, uma enorme diversidade de propostas eremíticas. Diversidade de carismas, estilos de vida e maneiras de organização. Existem eremitas urbanos; eremitas que habitam áreas rurais e até regiões desérticas; eremitas associados à Ordens religiosas (Cartuxos, Camaldolenses, Carmelitas); eremitas que vivem um ecletismo religioso ou pertenças religiosas distintas; eremitas que estão ligados diretamente a um bispo (eremitas diocesanos).

Porém, independente do formato e do estilo, o eremitismo é formado por homens e mulheres que, mesmo "na profundidade da sua solidão, não se subtraem à comunhão eclesial, antes pelo contrário servem-na com o seu específico carisma contemplativo". (VC 42). Assim, 
testemunham através da separação interior e exterior do mundo o caráter provisório do tempo presente, e pelo jejum e pela penitência atestam que o homem não vive só de pão, mas da Palavra de Deus (cf. Mt 4,4). Uma vida assim 'no deserto' é um convite aos indivíduos e à própria comunidade eclesial para nunca perderem de vista a vocação suprema, que é estar sempre com o Senhor. (VC 7).

A seguir, expressões destas formas antigas de consagração presentes na Arquidiocese de Belo Horizonte.

\subsection{Missionários Leigos Consagrados}

Tendo como fundador Dom Serafim Fernandes de Araújo e co-fundadora a Irmã Maria Dolores de Nazareth, os Missionários Leigos Consagrados têm seu início no dia 5 de abril de 1995, na cidade de Belo Horizonte, sendo denominados como Consagrados da Arquidiocese de Belo Horizonte. Em 10 de março de 2005 é que assumem o nome de Missionários Leigos Consagrados e em 8 de novembro de 2017 têm seu estatuto aprovado (Decreto 29/2017), assumindo o nome de Missionários Servos da Ternura de Deus e o estatuto de movimento eclesial.

Com um carisma e missão voltados para a formação cristã do laicato e a evangelização, esta Associação possui uma Regra de Vida e Estatutos. No seio desta família missionária existem diversos grupos: Missionários Consagrados (emitem votos religiosos), Casais Missionários, Leigos Enviados (assumem votos religiosos e atuam pastoralmente enviados em missões), Grupo Especial (geralmente, pessoas idosas com limitações, mas que podem colaborar de alguma maneira com a ação missionária) e Missionários Cooperadores (pessoas que se comprometem a sustentar os missionários por meio de orações). Embora cada membro viva em seu ambiente, organizam-se em Fraternidades e se encontram mensalmente para formação, partilha e ação evangelizadora. 


\subsection{Leigas Consagradas da Arquidiocese de Belo Horizonte}

Leigas Consagradas é a forma com que se denomina na Arquidiocese de Belo Horizonte a Ordo Virginum ${ }^{17}$, ou seja, a Ordem das Virgens, que, no caso desta circunscrição, também inclui as Viúvas.

Nesta arquidiocese, a consagração de mulheres diante do Arcebispo e com o compromisso com a Igreja local começa com Ivone Faria, que pede para fazer os votos diante de Dom Serafim Fernandes de Araújo, na década de 70. Mais tarde, se integram a este grupo as viúvas. Mais tarde ainda, o grupo se estruturou e começou a ter encontros frequentes para a prática da oração da liturgia das horas e para a partilha; além disso, se estabeleceu uma perspectiva formativa para estas consagradas.

Consagradas por meio do voto de castidade perpétua como sinal do Reino de Deus, dedicam-se “à oração e ao serviço da Igreja”. (VC 7). Sua ação é relacionada à inserção de cada uma na vida cotidiana (no século, segundo VC 42), sendo sal da terra e luz do mundo, fermento na massa onde estiverem, seja no mundo do trabalho ou na ação apostólica. Desta forma, algumas atuam em suas paróquias; outras, atuam em pastorais; e outras, ainda, atuam na estrutura administrativa da própria Igreja.

\subsection{Vida Eremítica}

Em Minas Gerais, e no que hoje é a Arquidiocese de Belo Horizonte, o eremitismo teve um grande florescimento, sobretudo a partir da ação de leigos consagrados que viviam ao redor de santuários. Foi assim com o ermitão Feliciano da Costa (Santuário do Senhor Bom Jesus de Matosinhos), que morre em 1765; o ermitão Lourenço (Santuário Nossa Senhora Mãe dos Homens, na Serra do Caraça), que morre em 1819; o ermitão Félix da Costa (que está na origem do Mosteiro de Macaúbas, no século XVIII); o ermitão Antônio da Silva,

\footnotetext{
17 Segundo explicou o arcebispo espanhol José Rodríguez Carballo, secretário da Congregação para os Institutos de Vida Consagrada e as Sociedades de Vida Apostólica, o termo "Ordo virginum" quer ser uma "expressão análoga às utilizadas para indicar outras 'Ordines' (Ordo episcoporum, Ordo Presbyterorum, Ordo diaconorum, Ordo viduarum)." (SCARAMUZZI, 2018).
} 
o Bracarena (+ 1784). Posteriormente, sua ermida veio a ser o Santuário Nossa Senhora da Piedade, onde congregou mais cinco ermitães. Mais tarde, irmã Germana e irmã Dionísia vivem como ermitãs até 1843, quando são obrigadas a se recolherem no Mosteiro de Macaúbas. ${ }^{18}$ Por fim, frei Rosário Joffily, op, viveu como eremita na Serra da Piedade (+ 2000).

Na atualidade ainda há eremitas que se fazem presentes na Arquidiocese de Belo Horizonte, tanto na perspectiva do eremitismo urbano, vivido em meio aos prédios da cidade de Belo Horizonte, quanto na perspectiva do eremitismo rural, havendo, inclusive, propostas pastorais interessantes que dialogam com as questões ambientais contemporâneas, com os excluídos e com o laicato.

\section{Conclusão}

É notório se perceber, no catolicismo contemporâneo e, sobretudo, na Arquidiocese de Belo Horizonte, a diversidade que lhe compõe. De alguma maneira, esta diversidade existe na pluralidade de grupos, propostas, teologias e estilos de vida. Além disso, no seio de cada grupo, também há propostas diversas, com finalidades e formas de se organizar também plurais. É assim que podemos perceber nas Novas Comunidades que algumas são procedentes da Renovação Carismática Católica, enquanto outras, também sendo Novas Comunidades e entendendo-se canonicamente como Associações de Fiéis, terão sua origem em outros grupos, com concepções teológicas distintas das do pentecostalismo católico. O mesmo se dá no que diz respeito às formas antigas de consagração. Grupos novos surgem, estilos diferentes de viver a consagração nestes grupos também existem e propostas de interação com os desafios da contemporaneidade também surgem.

Toda esta pluralidade aponta para uma perspectiva "construtivista" dessas expressões de consagração, entendendo o construtivismo como um processo em que os diversos grupos e comunidades lançam mão de repertório presente na cultura, na sociedade e na tradição católica e constroem, por meio de processos de bricolagem, a partir de sua singularidade e entendendo-se

\footnotetext{
${ }^{18}$ Um relato mais detalhado sobre estes eremitas se encontra em Carrato (1963, p. 181-222), no capítulo V desta obra, intitulado "Eremitas e santuários".
} 
inspirados pelo Espírito Santo, novas formas para dialogar com os desafios da contemporaneidade e com a tradição católica, procurando atualizá-la e renovála.

Ao mesmo tempo, a renovação acontece por meio de interações complexas entre comunidades, tradições, elementos culturais e sociais que são remodelados e ressignificados, assumindo perspectivas muito particulares que propiciam identidades a estes diversos grupos. Assim pode-se perceber a existência de certa porosidade entre diferentes grupos contemporâneos, construindo e ressiginificando sentidos e práticas de maneira polissêmica.

Diversidade esta que, quando vivida em comunhão e no respeito às diferenças, gera riqueza na ação pastoral-apostólico-evangelizadora e nos processos de autoconsciência de cada fiel que adere à perspectiva cristã-católica, que perceber-se-á a partir de sua singularidade diante dos vários estilos de vida cristã possíveis.

Urge, porém, que se invista na comunhão na comunidade eclesial arquidiocesana e, ao mesmo tempo, que não faltem esforços para a formação de todos os envolvidos com alguma forma de consagração. Somente assim conseguirão dialogar com a sociedade contemporânea belorizontina e, de alguma maneira, fazer a diferença onde se encontram, sobretudo para este momento da história arquidiocesana e da Igreja Católica.

\section{REFERÊNCIAS}

AGUIAR, Geraldo. O caminhar dos cristãos leigos e leigas: avanços, recuos e desafios. In: GRUPO DE REFLEXÃO DA COMISSÃO EPISCOPAL DE PASTORAL PARA O LAICATO DA CNBB. Sujeitos eclesiais: sal da terra e luz do mundo. Reflexões sobre o documento 105. São Paulo: Paulinas, 2017. p. 103-114.

ALIANÇA DE MISERICÓRDIA. Disponível em: https://misericordia.com.br. Acesso em: 12 fev. 2019.

ALMADA, Roberto. O cansaço dos bons: a logoterapia como alternativa ao desgaste profissional. São Paulo: Cidade Nova, 2013. 
ARAGÃO, Gilbraz. Os desafios dos movimentos e das novas comunidades. In: GRUPO DE REFLEXÃO DA COMISSÃO EPISCOPAL DE PASTORAL PARA O LAICATO DA CNBB. Sujeitos eclesiais: sal da terra e luz do mundo. Reflexões sobre o documento 105. São Paulo: Paulinas, 2017. p. 93-102.

ARAUTOS DO EVANGELHO. Disponível em: https://www.arautos.org/. Acesso em: 12 fev. 2019.

ARQUIDIOCESE DE BELO HORIZONTE. Estatuto do Movimento. Movimento Eclesial Missionários Servos da Ternura de Deus. 2017. Mimeo.

BERGER, Peter. O dossel sagrado: elementos para uma teoria sociológica da Religião. São Paulo: Paulus, 1985.

BÍBLIA DE JERUSALÉM. São Paulo: Paulus, 2002.

BINS, Rejane Maria Dias de Castro. Eclesialidade, novas comunidades e concílio Vaticano II. As novas comunidades como uma forma de autorrealização da Igreja. Cadernos de Teologia Pública, São Leopoldo, ano 13, v. 13, n. 106, p. 3-23, 2016.

BOFF, Leonardo. A Trindade é a melhor comunidade. Petrópolis, Vozes, 1988.

BRANDÃO, Carlos Rodrigues. Fronteira da fé - Alguns sistemas de sentido, crenças e religiões no Brasil de hoje. Estudos avançados, São Paulo, v. 18, n. 52, p. 261-288, 2004 .

BRANDÃO, Carlos Rodrigues. Ser católico: dimensões brasileiras. Um estudo sobre a atribuição da religião. In: SACHS, Viola et al. Brasil \& EUA: religião e identidade nacional. Rio de Janeiro: Graal, 1988.

BRIGHENTI, Agenor. A Igreja do futuro e o futuro da Igreja: perspectivas para a evangelização na aurora do terceiro milênio. São Paulo: Paulus, 2001.

CARRANZA, Brenda; MARIZ, Cecília Loreto. Novas comunidades católicas: por que crescem? In: CARRANZA, B.; MARIZ, C. L.; CAMURÇA, M. Novas comunidades católicas: em busca do espaço pós-moderno. Aparecida: Ideias \& Letras, 2009. p. 139170 .

CARRATO, José Ferreira. As Minas Gerais e os primórdios do Caraça. São Paulo: Companhia Editora Nacional, 1963.

CNBB. Os cristãos leitos e leigas na Igreja e na sociedade. Documentos da CNBB, 105. São Paulo: Paulinas, 2016.

CNBB. Subsídios doutrinais da CNBB. Igreja particular, movimentos eclesiais e novas comunidades. São Paulo: Paulinas, 2005.

CÓDIGO DE DIREITO CANÔNICO (CIC). São Paulo: Loyola, 1983.

CODIN, Victor; ZEVALLOS, Noé. Vida religiosa: história e teologia. Petrópolis: Vozes, 1987. 
COMSHALOM.COM. Disponível em: https://www.comshalom.org/. Acesso em: 30 jul. 2019.

COMUNIDADE ÁRVORE DA VIDA. Disponível em:

http://comunidadearvoredavida.com.br/po/missao/. Acesso em: 02 ago. 2019.

COMUNIDADE CANÇÃO NOVA. Estatuto Canônico da Comunidade Canção Nova. Disponível em:

https://img.cancaonova.com/cnimages/especiais/uploads/sites/11/2017/o3/CancaoN ova_Estatuto_Canonico_230614.pdf. Acesso em: 13 fev. 2019.

COMUNIDADE CATÓLICA NOVA ALIANÇA. Disponível em:

www.novaalianca.com.br. Acesso em: 30 jul. 2019.

COMUNIDADE CATÓLICA SHALOM. Estatutos. Aquiraz: Edições Shalom, 2012.

CONGREGAÇÃO PARA OS INSTITUTOS DE VIDA CONSAGRADA E AS

SOCIEDADES DE VIDA APOSTÓLICA. Ecclesiae sponsae imago (ESI). 2017.

Disponível em:

http://www.vatican.va/roman_curia/congregations/ccscrlife/documents/rc_con_ccsc rlife_doc_20180608_istruzione-ecclesiaesponsaeimago_sp.html. Acesso em: 12 ago. 2019.

CONSELHO EPISCOPAL LATINO-AMERICANO. Conclusões da Conferência de Medellín - 1968. Texto oficial. São Paulo: Paulinas, 2010.

CONSELHO EPISCOPAL LATINO-AMERICANO. Documento de Santo Domingo. Petrópolis: Vozes, 1993.

FERREIRA, Wagner. As novas comunidades no contexto sócio-cultural contemporâneo. Cachoeira Paulista: Editora Canção Nova, 2011.

FIORES, Stefano de; GOFFI, Tullo. Dicionário de espiritualidade. São Paulo: Paulus, 1993.

FRANCISCO, Fernando Rodrigues. As contribuições das novas comunidades cristãs para a teologia do laicato. Reveleteo, São Paulo, v. 6, n. 9, p. 39-54, jan./jun. 2012.

FRATERNIDADE DAS NOVAS COMUNIDADES DO BRASIL. Novas comunidades: primavera da Igreja. São Paulo: Editora Canção Nova, 2008.

GERALDO, Denilson. As formas de vida consagrada como dom do Espírito Santo à Igreja. Revista de Cultura Teológica, São Paulo, v. 19, n. 74, p. 87-109, abr./jun. 2011.

GRUPO DE REFLEXÃO DA COMISSÃO EPISCOPAL DE PASTORAL PARA O LAICATO DA CNBB. Sujeitos eclesiais: sal da terra e luz do mundo. Reflexões sobre o documento 105. São Paulo: Paulinas, 2017.

HÈRVIEU-LÉGER, Daniele. O peregrino e o convertido: a religião em movimento. Petrópolis: Vozes, 2008.

JOÃO PAULO II, Papa. Christifideles laici. São Paulo: Paulinas, 1990. 
JOÃO PAULO II, Papa. Messagio al Congresso mondiale dei movimenti ecclesiali. L'Osservatore Romano, 28 maggio 1998.

JOÃO PAULO II, Papa. Vita consecrata. São Paulo: Paulinas, 1996.

MARIZ, Cecília L.; LOPES, Paulo Victor Leite. O reavivamento católico no Brasil e o caso da Toca de Assis. In: TEIXEIRA, Faustino; MENEZES, Renata. Catolicismo plural: dinâmicas contemporâneas. Petrópolis: Vozes, 2009. p. 75-108.

MARIZ, Cecília. A Renovação Carismática Católica: uma igreja dentro da Igreja? Civitas, Porto Alegre, v. 3, n. 1, p. 169-186, jun. 2003.

MARIZ, Cecília. Catolicismo no Brasil contemporâneo: reavivamento e diversidade. In: TEIXEIRA, Faustino; MENEZES, Renata. As religiões no Brasil: continuidades e rupturas. Petrópolis: Vozes, 2006. p. 53-68.

MIRANDA, Júlia. Carisma, sociedade e política: novas linguagens do religioso no político. Rio de Janeiro: Jorge Zahar, 1999.

\section{MISSIONÁRIOS CONSAGRADOS. Regra de vida dos Missionários Consagrados} (as). 2005. Mimeo.

PINHEIRO, Luiz Antônio. Expressões leigas da vida do Povo de Deus na Arquidiocese de Belo Horizonte. In: BOSCHI, Caio César; PINHEIRO, Luiz Antônio. A arquidiocese de Belo Horizonte e o laicato. Belo Horizonte: Editora PUC Minas, 2015. p. 95-158.

PORTELA, Rodrigo. Em busca do dossel sagrado: a Toca de Assis e as novas sensibilidades religiosas. 2009. Tese (Doutorado em Ciência da Religião) Universidade Federal de Juiz de Fora, Juiz de Fora, 2009.

RATZINGER, Joseph. I movimenti ecclesiali e la loro collocazione teológica. In: PONTIFICIUM CONSILIUM PRO LAICIS. I movimenti nella chiesa. Atti del congresso mondiale dei movimenti ecclesiali. Cittá del Vaticano: Libreria Editrice Vaticana, 1999.

RUMSTAIN, Ariana; ALMEIDA, Ronaldo de. Os católicos no trânsito religioso. In: TEIXEIRA, Faustino; MENEZES, Renata. Catolicismo plural: dinâmicas contemporâneas. Petrópolis: Vozes, 2009. p. 31-55.

SANCHIS, Pierre. As religiões dos brasileiros. Horizonte: revista de estudos de teologia e ciências da religião, Belo Horizonte, v. 1, n. 2, p. 28-43, $2^{\circ}$ sem. 1997.

SANCHIS, Pierre. Religiões, religião... Alguns problemas do sincretismo no campo religioso brasileiro. In: SANCHIS, Pierre (org.). Fiéis e cidadãos: percursos de sincretismo no Brasil. Rio de Janeiro: Ed UERJ, 2001.

SANTOS, Rocélia Barbosa dos. Novas comunidades católicas: gênese, confrontos e desafios comunicativos na sociedade contemporânea. 2014. Dissertação (Mestrado em Comunicação Social) - Pontifícia Universidade Católica do Rio de Janeiro, Rio de Janeiro, 2014. 
SCARAMUZZI, Iacopo. Virgens consagradas. O Vaticano identifica um fenômeno em expansão. 2018. Disponível em: http://www.ihu.unisinos.br/78-noticias/580579virgens-consagradas-o-vaticano-identifica-um-fenomeno-em-expansao. Acesso em: 10 ago. 2019.

SHALOM. Estatutos da Comunidade Católica Shalom. Fortaleza: Edições Shalom, 2012.

SILVA, Emanuel Freitas da. Como se produz um novo católico carismático: elementos da espiritualidade da comunidade Shalom. Caminhos, Goiânia, v. 17, n. 1, p. 43-64. jan./jun. 2019.

SOUZA, Carlos Frederico Barboza de. A Conferência Episcopal de Medellín: inspiração para uma mística latino-americana e caribenha. Horizonte, Belo Horizonte, v. 16, n. 50, p. 698-728, maio/ago. 2018.

TEIXEIRA, Faustino. Faces do catolicismo brasileiro contemporâneo. In: TEIXEIRA, Faustino; MENEZES, Renata. Catolicismo plural: dinâmicas contemporâneas. Petrópolis: Vozes, 2009. p. 17-30.

TOCA DE ASSIS. Disponível em: http://tocadeassis.org.br/. Acesso em: 10 jun. 2019.

VATICANO II. Compêndio do Vaticano II: constituições, decretos, declarações. Petrópolis: Vozes, 1983.

ZANOTO, Gizele. Os Arautos do Evangelho no espectro católico contemporâneo. Disponível em: http://www.dhi.uem.br/gtreligiao/pdf9/13.pdf. Acesso em: 06 maio. 2019. 